\title{
Phase Equilibrium for Clathrate Hydrates Formed with Difluoromethane and N-Methylpiperidine for Hydrate-Refrigeration System
}

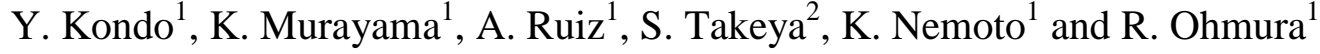 \\ ${ }^{1}$ Department of Mechanical Engineering, Keio University \\ Kohoku-ku, Yokohama 223-8522 (Japan) \\ Phone/Fax number: +81 45 566-1813/+81 45566 1495, e-mail: rohmura@mech.keio.ac.jp \\ ${ }^{2}$ National Institure of Advanced Industrial Science and Technology (AIST). \\ Tsukuba, Ibaraki 305-8565 (Japan)
}

\begin{abstract}
This paper reports the pressure-temperature conditions for the three-phase aqueous liquid + hydrate + vapor equilibrium in the hydrate formed with water, difluoromethane and methylpiperdine as large molecule guest compound (LMGC). The aim of the study is to obtain a hydrate formed in mild pressure-temperature conditions which could be applied to various technologies. To measure the pressure- temperature phase equilibrium, isochoric method ${ }^{[1]}$ was used. The pressure and temperature ranges of the present measurements are from 61.9 to $104.2 \mathrm{kPa}$ and from 259.3 to $272.2 \mathrm{~K}$. Obtained results were comparatively mild conditions than the phase equilibrium $p-T$ condition of the structure I hydrates formed with water + difluoromethane. To alleviate the phase equilibrium condition, the LMGCs showed its significance through this study. In addition, the cage structure of formed hydrates was measured by powder X-ray diffraction measurements. The hydrate samples were made using the difluoromethane and $\mathrm{N}$-methylpiperidine. The measurement results indicated the cage structure of hydrate as structure $\mathrm{H}$. Thus, the molecular size of difluoromethane was confirmed as the suitable size for the small cages of structure $\mathrm{H}$.
\end{abstract}

\section{Key words}

Clathrate hydrate, Hydrate-based heat pump/ refrigeration system, Difluoromethane, Methylpiperidine

\section{Introduction}

Development of technologies brought dramatic changes to the human's lifestyle. Sophisticated society granted with convenience system demand in meantime large energy consumption. Most of the energy converted from heat energy by burning fossil fuels, which resulted to shortening of resources and climate affect. To prevent the situation getting worse, new and clean energy sources and the technology for practical use are necessary. As for one method of solution, a clathrate hydrate could be the one.

The clathrate hydrate (or hydrate) is crystalline solid compound which is consisted of cages structured with hydrogen-bonded water molecules and guest molecules encapsulated. From previous studies, three different crystallographic structures are confirmed as the basic configuration; structure I (sI), structure II (sII), and structure $\mathrm{H}(\mathrm{sH})^{[2]}$. The $\mathrm{sH}$ hydrate was first found in
1987 by Ripmeester et al. and reported the unit crystal as a hexagonal structure, in spite of the sI and sII consisted of cubic unit crystal. In addition it reported that the $\mathrm{sH}$ consists small cages $\left(5^{12}\right.$ and $4^{3} 5^{6} 6^{3}$ cages) and large cages $\left(5^{12} 6^{8}\right.$ cage $)$. The cage structure depends on the shape and size of guest molecules. The hydrates have commercially favourable properties, such as large gas capacity, large formation/decomposition heat, gas selectivity and so on. Utilizing these properties, the hydrate-based applications are proposed such as storage media of natural gas and hydrogen, $\mathrm{CO}_{2}$ capture, and hydrate-based heat pump. By replacing the present technology with the hydrate based technologies, higher energy efficiency and lower environmental effects are expected. For instance, the previous study calculated the hydrate-based refrigeration system using the hydrate, and itindicated that the energy efficiency will be higher than that of the current system ${ }^{[3]}$. One of the bottlenecks the hydrate-based technologies have is the unrealistic conditions of pressure and temperature. The simple hydrate (sI) formed with methane and water forms at the pressure of $37 \mathrm{MPa}$ at $296.6 \mathrm{~K}^{[2]}$. The alleviation of phase equilibrium is the key for applications of hydrates. In general, sII and $\mathrm{sH}$ hydrates form in relatively lower pressure compared to s I hydrates. Especially, sH hydrates are well known to have the higher gas capacity than the sII hydrates, inevitably the commercial use is expected in future.

The formation conditions of $\mathrm{sH}$ hydrates vary depending on the relations between guest molecules and cages. These hydrates consist of small cages and large cages, and each cage encapsulates a small gaseous molecule (e.g. methane, carbon dioxide, fluoromethane) or large molecule guest compounds (LMGCs). The previous studies showed the relation of LMGCs encapsulated in the large cages and the thermodynamic stability of $\mathrm{sH}$ hydrates ${ }^{[4]}$. This study on the other hand focused on the effect of the molecular size and shape inside the small cages of $\mathrm{sH}$ hydrates. Uchida et al. ${ }^{[5]}$ reported the critical molecular size for the guest compounds that can be encapsulated in the small cages of sI hydrates. It says that fluoromethane (HFC-41) and difluoromethane (HFC-32) can enter the sI small cages 
( $5^{12}$ and $5^{12} 6^{2}$ cages). HFCs are suitable compounds to evaluate their effects on the small cages due to the gradual increase in volumetric size corresponding with the number of carbon-fluoride bond. HFC-41 is smaller than HFC-32, but the HFC-32 is smaller than trifluoromethane (HFC23). The factor of HFCs' molecular size can apply to determine the optimum molecular size of guest molecules within the small cages. It is already known that HFC-23 can only enter the $5^{12} 6^{2}$ small cages unless of the high pressure ${ }^{[6]}$, thus the HFC-32 was approximated as the suitable molecular size encapsulated in the small cages of $\mathrm{sH}\left(5^{12}\right.$ and $4^{3} 5^{6} 6^{3}$ cages $)$.

Hence, in the present study the measurement of four (Ice$\mathrm{H}-\mathrm{V}-\mathrm{L}_{\mathrm{g}}$ or $\mathrm{L}_{\mathrm{w}}-\mathrm{H}-\mathrm{V}-\mathrm{L}_{\mathrm{g}}$ ) phase equilibrium conditions of the hydrate formed in difluoromethane $+\mathrm{N}$-methylpiperidine + water system was done. Based on powder X-ray diffraction (PXRD) measurements the cage structure of formed hydrate was identified.

\section{Methods and Apparatus}

\section{Phase Equilibrium Measurements}

The apparatus is schematically illustrated in figure 1 . Water was deionized and distilled in the laboratory. The ice was obtained by freezing the processed water with liquid nitrogen, grained finely into ice powders with the diameter under $1 \mathrm{~mm}$. HFC-32 and methylpiperidine were used in the purity as listed in table Inside the stainless cylinder the methylpiperidine- dissolved water was sealed. The volumeof the cylinder is $71 \mathrm{~cm}^{3}$. Gaseous guest compounds were then charged inside the cylinder. The sealed cylinder was immersed in a temperature- controlled ethylene glycol bath. The apparatus used a PID- controlled heater (TM-1, As One Co., Ltd.) and an immersion cooler (ESC-30, Tokyo Rikakikai Co., Ltd.) to maintain the stable temperature. The system measured pressure and temperature data using instruments listed in table 2 . The fluids and hydrate crystals inside the test vessel were agitated with an electromagnetic stirrer, which was inserted through the vessel's lid. The impeller was set to rotate at $300 \mathrm{rpm}$.

The equilibrium temperature and pressure conditions for four-phase or three-phase equilibrium systems were measured with the isochoric method described by Danesh et al. ${ }^{[1]} .12 \mathrm{~g}$ of the ice powders were prepared at the temperature of $220 \mathrm{~K}$ preventing from melting. The test vessel was cooled at the same temperature as well. The powders were filled inside the vessel to measure (Ice $+\mathrm{H}$ $+\mathrm{V}$ or $\mathrm{L}_{\mathrm{w}}-\mathrm{H}-\mathrm{V}$ ) three phase equilibrium. For the (Ice-H$\mathrm{V}-\mathrm{L}_{\mathrm{g}}$ or $\mathrm{L}_{\mathrm{w}}-\mathrm{H}-\mathrm{V}-\mathrm{L}_{\mathrm{g}}$ ) four phase equilibrium condition measurements, same amount of the ice powders and 4.8 $\mathrm{cm}^{3}$ of $\mathrm{N}$-methylpiperidine were used.

$\mathrm{N}$ - methylpiperidine was also cooled below the freezing point using liquid nitrogen and grained into powder form before mixing together with the ice powders. The amount of each compounds was calculated using the stoichiometric amount needed for the sH hydrate conformation. However according to the Gibb's phase rule, the degree of freedom $F$ of the experimental system is determined to be unity; in other words the $p-T$ equilibrium condition will be determined not relied on the molar mass ratio of guest compounds. The both powders were inserted in the vessel and experimental procedures were done at temperatures between (259.3 and 272.2) K and pressures between (61.9 and 104.2) $\mathrm{kPa}$. The initial conditions of $p$ - $T$ were set at the range of (60 to 105$) \mathrm{kPa}$ and (260 to 273) K where the hydrate doesn't exist certainly. When the pressure stabilized, $T$ was decreased in order to form the hydrates. The inner pressure of vessel will decrease due to the gaseous guest compounds captured by the hydrates. If the pressure stabilized again, temperature $T$ was increased by steps of $0.2 \mathrm{~K}$. The procedure of temperature increase was repeated when the pressure stabilized in the difference of $0.1 \mathrm{KPa}$ within the span of $8 \mathrm{~h}$. At the point of hydrate dissociation completed the $p$ - $T$ gradient will become smaller, due to the minimal $p-T$ changes of gaseous and aqueous phases. In the experimental procedure, the point before the slope of $p-T$ changes was defined as the four or three phase equilibrium. Changing the initial condition, several four or three phase equilibrium condition data was taken at the desired temperature-pressure range.

\section{Powder X-ray diffraction measurements}

The crystalline structure was measured using the powder $\mathrm{x}$-ray diffraction. The hydrate crystal sample was prepared using the apparatus for the phase equilibrium measurement. The powdered ice and difluoromethane, $\mathrm{N}$ methylpiperidine were prepared by same amount as the phase equilibrium measurement. $P-T$ condition was set at $p=95 \mathrm{kPa}$ and $T=263 \mathrm{~K}$. The pressure was kept under $100 \mathrm{kPa}$ avoiding the formation of simple difluoromethane sI hydrate. As the hydrate formation proceeds, the pressure in the vessel will decrease to the equilibrium condition. When the pressure stabilized, the difluoromethane was refilled and allowed the further hydrate formation. The refilling steps were repeated until all the ice formed into the hydrates at the point where no further pressure reduction was observed. The stabilized vessel was immersed in a liquid nitrogen bath and decreased the temperature under $220 \mathrm{~K}$, in order to prevent the hydrate dissociation. The vessel was quickly disassembled out of the pool and the lower vessel containing the hydrate was immersed in the pool again. The sample hydrate was obtained by this procedure.

The obtained hydrate sample was stored in a container at the temperature below $100 \mathrm{~K}$ and finely powdered in a nitrogen atmosphere. The powdered samples were toploaded on a copper $(\mathrm{Cu})$ specimen holder. Using the $\mathrm{Cu} \mathrm{K} \alpha$ radiation by $\theta / 2 \theta$ step scan mode with a step width of $0.02^{\circ}(40 \mathrm{kV}, 40 \mathrm{~mA}$; Rigaku model Ultima III) the PXRD measurements were done. Analysis of the lattice constants was done by a full-pattern fitting method using the Rietveld program RIETAN-FP. $13^{[7]}$.

Table 1 Materials used in the present study

\begin{tabular}{|c|c|c|c|}
\hline Chemical & Supplier & & Purity \\
\hline Difluoromethane & $\begin{array}{l}\text { Takachiho } \\
\text { Industrial }\end{array}$ & Chemical & $>99.9$ \\
\hline $\mathrm{N}$-methylpiperidine & Sigma Aldrich & & $>99.0$ \\
\hline
\end{tabular}

Table 2 Instruments used in the present study

\begin{tabular}{|c|c|c|}
\hline Instrument & Supplier & Uncertainty \\
\hline Strain-gauge pressure & PAB-A-200KP, Kyowa & $\pm 0.14 \mathrm{kPa}$ \\
\hline transducer & Electric Instruments Co. & \\
\hline $\begin{array}{l}\text { Platinum resistance } \\
\text { thermometer }\end{array}$ & Ichimura Metal Co., Japan & $\pm 0.1 \mathrm{~K}$ \\
\hline
\end{tabular}




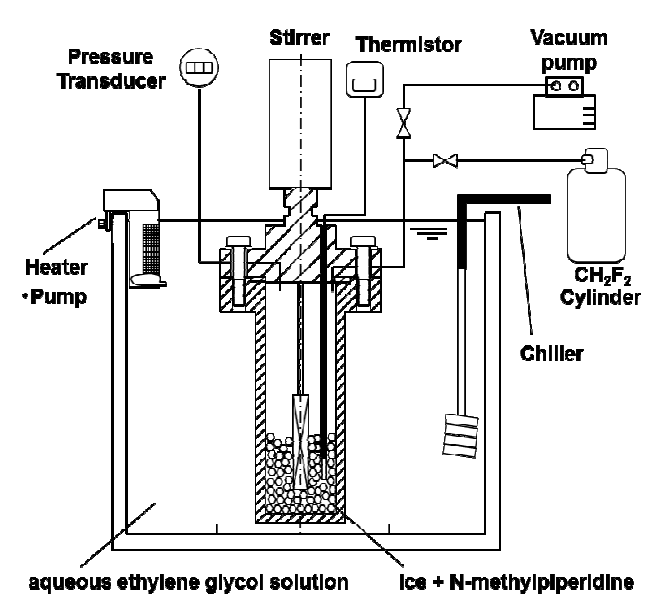

Fig. 1. Schematic of the experimental apparatus.

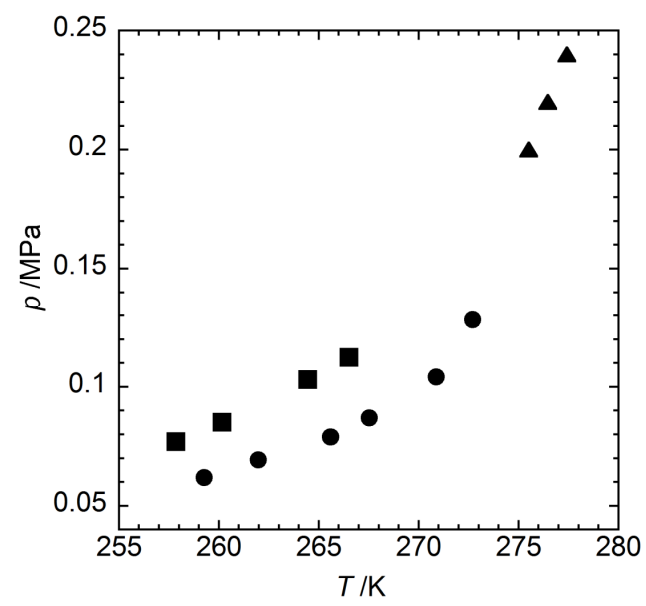

Fig. 2. $p-T$ data of phase equilibrium condtions for hydrates formed in (HFC-32 + water) and (HFC-32 + N-methylpiperidine + water) systems. $\boldsymbol{\Delta}$ : $\left(\right.$ HFC-32+ water) system ${ }^{(8)}$, $\mathbf{~ : ~ ( H F C - 3 2 ~ + ~ w a t e r ) ~}$ system, $\bullet$ : (HFC-32 + N-methylpiperidine + water) system.

\section{Results and Discussion}

Figure 2 shows the $p-T$ data of the four-phase (Ice-H-V- $\mathrm{L}_{\mathrm{g}}$ or $\left.\mathrm{L}_{\mathrm{w}}-\mathrm{H}-\mathrm{V}-\mathrm{L}_{\mathrm{g}}\right)$ equilibrium in the (HFC-32+Nmethylpiperidine + water) system and the three-phase (Ice-H-V or $\mathrm{L}_{\mathrm{w}}-\mathrm{H}-\mathrm{V}$ ) equilibrium in the (HFC-32 + water) system. The $p-T$ data of the (HFC-32 + water) system above the freezing point are also plotted in the Figure $2^{[8]}$. Comparing the two systems, this study showed the lower pressure equilibrium at a given temperature. At $267.5 \mathrm{~K}$, the difference between the two systems' equilibrium pressure is approximately $30 \mathrm{kPa}$. Possible reason for the moderated pressure condition could be the difference of cage structures. The water + HFC-32 system are reported to form structure I hydrates. The addition of $\mathrm{N}$ methylpiperidine to the system may result in the foromation of a double hydrate. Considering the molecular size of $\mathrm{N}$-methylpiperidine, the double hydrate's structure is estimated to be a structure $\mathrm{H}$ hydrate, allowing HFC-32 to enter the small cages $\left(5^{12}\right.$, $\left.4^{3} 5^{6} 6^{3}\right)$ and $\mathrm{N}$-methylpiperidine to enter the large cage $\left(5^{12} 6^{8}\right)$.

Figure 3 and 4 shows the result of PXRD measurements done at the temperature $100 \mathrm{~K}$ and $153 \mathrm{~K}$. The measurements indicated the cage structure as $\mathrm{sH}$ hydrates, not as the sI hydrates. The data showed the lattice

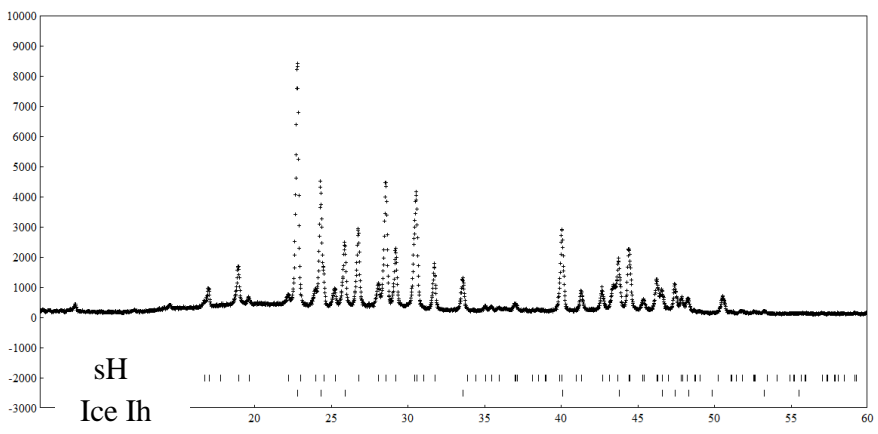

Fig. 3. PXRD patterns for structure $\mathrm{H}$ hdyrate at $100 \mathrm{~K}$ : difluoromethane $+\mathrm{N}$-methylpiperidine hydrate. The tick marks in the lower part represent the calculated peak positions for the $\mathrm{sH}$ hydrate and hexagonal ice.

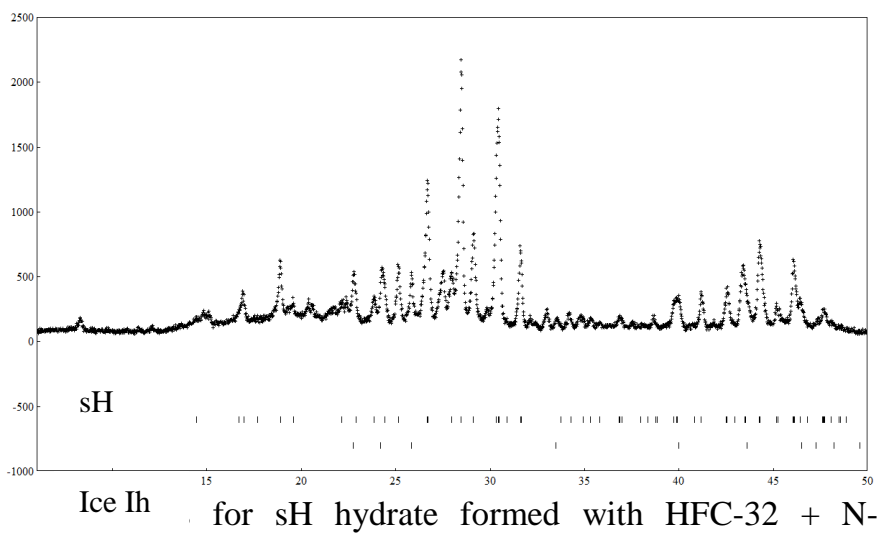

Fig. 4. PXRD patterns for structure $\mathrm{H}$ hdyrate at $153 \mathrm{~K}$ : difluoromethane $+\mathrm{N}$-methylpiperidine hydrate. The tick marks in the lower part represent the calculated peak positions for the $\mathrm{sH}$ hydrate and hexagonal ice.

methylpiperidine + water as $a=12.2(2) \AA$ and $c=9.98$ (2) $\AA$ at $100 \mathrm{~K}, a=12.3(3) \AA$ and $c=10.0$ (2) $\AA$ at $153 \mathrm{~K}$. Imasato et al. ${ }^{[9]}$ reported the lattice constant of sI hydrates formed with the methane +1 -methylpiperidine as $a=$ 12.2(2) $\AA$ and $c=10.0$ (2) $\AA$ at $153 \mathrm{~K}$. The difference of the lattice constant could relate to the molecular mass and radii of the both difluoromethane and methane.

Compared to the methane, difluoromethane has 2 fluorides replaced instead of the hydrogen atom from the methane. Therefore the radii and the molecular mass of the difluoromethane are greater than that of the methane. In the previous study it was also estimated that the fluoromethane to enter the small cages of $\mathrm{sH}$ hydrate ${ }^{[10]}$ though it did not clarify the point whether the difluoromethane could be the guest compound as well or not. This study indicates the capability of difluoromethane to enter the small cages ( $5^{12}$ and $4^{3} 5^{6} 6^{3}$ cages) of $\mathrm{sH}$ hydrate.

The hydrate-based refrigeration system model was proposed by Ogawa et al. ${ }^{[3]}$. In the paper, the ratio of the cooling energy output to the sum of the power inputs is calculated as $\mathrm{COP}=8.0$. The suitable temperature range is from (278 to 300$) \mathrm{K}$ whereas the refrigeration space temperature and the heat- releasing environmental temperature. In this study, the temperature range was limited below $275 \mathrm{~K}$. Therefore, expanding the range of temperature measurement is needed for the further improvements. The pressure condition, however, is near the atmospheric pressure. Considering the required power inputs, moderated pressure condition is attractive for the 
industrial usages, especially for the application used under the freezing point of water.

\section{Conclusion}

The phase equilibrium conditions were measured for the systems of (HFC-32+ water) and (HFC-32+ methylpiperidine + water) within a temperature range of 259.3 to $272.2 \mathrm{~K}$. The results indicate that the system with methylpiperidine had milder phase equilibrium conditions. The simple hydrate formed with only the HFC-32 is identified as the $\mathrm{sI}^{[8]}$, however in this study the cage structure differed by adding the methylpiperidine as the LMGCs. The PXRD measurements were hold in order to determine the cage structures of formed hydrates. With the obtained results it can safely declared that the cage structure formed in present study was $\mathrm{sH}$ hydrates. Furthermore, the lattice constant of the hydrate formed with difluoromethane and $\mathrm{N}$-methylpiperidine differed from that of the hydrate formed with methane and $\mathrm{N}$ methylpiperidine. The geometric status of each molecular should be responsible of the difference. This study was able to conduct the basic research about the small cages and guest molecules encapsulated in the hydrate. For the further understanding, the studies on the guest molecules and the small cages could be done with more details.

Compared to the simple hydrate formed with difluoromethane and water, the decrease in equilibrium pressure was observed below $275 \mathrm{~K}$ which limits its possible applications. Considering the operation environment, it will be not suitable for the residential heat pump/refrigeration system however may be used for the different applications. Since the pressure conditions were mild, the technologies applied within low temperature range are preferable.

\section{Acknowledgments}

This study was supported by a Keirin-racing-based research-promotion fund from the JKA Foundation Grant Number 2018M-170 and by JSPS KAKENHI Grant Number 25289045.

\section{References}

[1] A.Danesh, B.Tohidi, R. W. Burgass, A. C. Todd, "Hydrate equilibrium data of methyl cyclopentane with methane or nitrogen." in Chem. Eng. Res. Des. 1994, Vol. 72, pp. 197-200.

[2] E. D. Sloan, Clathrate Hydrates of Natural Gases, Marcel Dekker Inc., New York (1998).

[3] T.Ogawa, T. Itoh, K. Watanabe, K. K. Tahara, R. Hiraoka, J. Ochiai, R. Ohumra, Y. H. Mori, "Development of a novel hydrate-based refrigeration system: A preliminary overview", in Appl. Therm. Eng., 2005, Vol. 26, pp. 2157-2167.

[4] S. Takeya, R. Ohmura, "Phase Equilibrium for Structure I and Structure H formed with Methylfluoride and Methylcyclohexane" in J. Chem. Eng. Data, 2007, Vol. 52, pp. 635-638.

[5] T. Uchida, R. Ohmura, A. Hori, "Critical size for guest molecules to occuby dodecahedral cage of clathrate hydrates", in J. Phys. Chem. C. 2008, Vol. 112, pp. 4719-4724.

[6] K. Sugahara, M. Yoshida, T. Sugahara, K. Ohgaki, "HighPressure Behavior and Cage Occupancy for the $\mathrm{CF}_{4}$ Hydrate System", in J. Chem. Eng. Data, 2004, 49, 326-329.

[7] F. Izumi, K. Momma, "Three-dimensional visualization in powder diffraction", in Solid State Phenom., 2007, 130, 15-20.

[8] S. Imai, K. Okutani, R. Ohmura, Y.H. Mori, "Phase equilibrium for clathrate hydrates formed with difluoromethane + either cyclopentane or tetra-n-butylammonium bromide", in J. Chem. Eng. Data, 2005, Vol. 50, pp. 1783-1786.

[9] K. Imasato, K. Murayama, S. Takeya, S. Alavi, R. Ohmura, "Effect of nitrogen atom substitution in cyclic guests on properties of structure H clathrate hydrates", in Can. J. Chem. 93, 906-912

[10] J. A. Ripmeester, C.I. Ratcliffe, " ${ }^{129}$ Xe NMR Studies of Clathrate Hydrates: New Guests for Structure II and Structure H”, in J. Phys. Chem. 1990, 94, 8773-8776. 